\title{
Agricultural Postgraduate Education and Training in the Problems and Countermeasures
}

\author{
Muwei Zhang \\ Jilin Agricultural University College of Humanities \\ zmw0302129@163.com
}

\begin{abstract}
At present, the Graduate Education of Agricultural Science and there are not enough students, small-scale culture, the culture conditions are relatively backward, stagnant applied talents training and other issues, this leads to a high level of agricultural advanced science and technology talent training is relatively scarce, difficult to adapt to the rapid development of modern agriculture needs. In this regard, this paper should increase efforts to promote modern agricultural science and the development of new content, strengthen professional degree graduate education, promote comprehensive reform in the graduate training mode, management system, teacher team building, etc., in order to achieve the Postgraduate Education and Training in Agricultural qualitative leap.
\end{abstract}

Keywords: Agricultural Science graduate; Education; Training.

\section{Introduction}

Since the reform and opening up, China's agricultural postgraduate education has been developing rapidly, the recruitment of students scale expands unceasingly, continue to regulate the management system, we have trained a large number of agricultural high-level personnel, teaching and research for China's agricultural and agricultural modernization has made tremendous contributions. However, in recent years, along with traditional agriculture to modern agriculture transformation strategy, the agricultural sector and agribusiness management demand for more and more senior management personnel, the quality requirements are also increasing [1]. Therefore, higher agricultural education, especially agricultural postgraduate education and training shoulders for agricultural modernization to provide personnel support and intellectual contributions of historical mission and the reality of dual task. We are facing new opportunities and challenges.

\section{Problems}

\subsection{The number of postgraduate students in agricultural universities is inadequate.}

The level of agricultural development lags behind other industries, agriculture and rural development level is relatively backward. Agriculture agricultural science and technology personnel work conditions, low treatment of practical problems such as intangible will reassure students does love the enthusiasm of farmers, agricultural subject is conveniently become unpopular subjects. From the National Graduate examination admission requirements, the admission of Agriculture and Forestry is relatively low. This will be hard to attract more talented persons in agricultural science and career development. Directly lead to agricultural senior talent lack severely restricted the modern agriculture and rural development. One of the first tasks facing the current agricultural postgraduate education is to train a large number of senior personnel agriculture.

2.2 Relative to the scale of graduate education, expanded year by year, the improvement of the agricultural condition of graduate student training relative lag.

Improve agricultural class of graduate students cultivation is lagging behind, mainly in terms of experimental conditions, the conditions of teachers. Agricultural graduate education funds than other disciplines is still inadequate. Over the years, agricultural postgraduate education funding to the national government appropriations, over a single channel and a small amount of culture required depends on the subject and tutor research funding support actual expenditure to a great extent. This has seriously hampered the improvement of culture conditions, and even improves the quality of 
agricultural postgraduate cultivation. The quality of Tutors is an important aspect of culture conditions. It should be noted, tutor team lack some old ideas, forward-looking poor, knowledge is not extensive, low theoretical level academic standards of the people there. In particular, not only learning but also teaching people to teach people not many mentors in life. Moreover, the situation of no teacher doctorate guide doctoral still exists. Doctoral tutor period situation is more serious. Great efforts to strengthen the training of young doctoral tutor, improve the overall quality of teacher team without delay.

\subsection{Traditional agricultural postgraduate education is more emphasis on academic personnel} training, lack of innovation and practical ability.

Traditional agricultural graduate education is more emphasis on academic personnel training, knowledge transfer heavy and light capacity-building; instill teaching methods mainly based teaching in the form of lectures, ignoring the self-learning ability, innovation ability, innovation ability and the ability to solve practical problems of agricultural production and so on [2]. With the development of science and technology progress and modern agriculture, academic talent has been far can not meet the needs of social development. China since the beginning of 2000 to recruit "Agricultural Extension Master", "Master of Veterinary Medicine" and other professional postgraduate degree, compared to more developed countries, Postgraduate Education for the late start, but also to recruit smaller scale, modern agriculture can not meet the development needs of high-level application-oriented talents. In terms of social acceptance, there is still a considerable number of people do not know enough agricultural professional degree, Applied Talents are still misunderstanding, fear obtained a Master degree level lower than academic.

\section{Improve countermeasures and suggestions of agricultural postgraduate education training quality.}

\subsection{Increase efforts to promote modern agricultural science and the development of new content, dedicated to the cause of agricultural students to noble human spirit.}

Connotation of modern agriculture fully reflected in the overall production of organic, economic, technological, social and ecological system formed by five. This is not only modern agricultural science on the subject, but also involves management science, life science, information science, law, and other interdisciplinary scientific knowledge into a comprehensive large scientific system [3]. Therefore, to enhance the people on the new connotation of modern agricultural science awareness and social acceptance of modern agricultural science, in order to enhance the attractiveness of Agricultural Science and postgraduate education; to attract more outstanding students to join the agricultural undertaking development, to develop their agriculture and the sense of social responsibility and mission. Develop their courage to face the present situation of agriculture backward and tough working environment, dedicated, dedication, devotion to the cause of agricultural determinedly as noble human spirit.

3.2 Vigorously develop the agricultural professional degree postgraduate education, more emphasis on application-oriented talents.

Our Agricultural Science and Professional Education and the developed countries there are still significant gaps in comparison; we can not meet the needs of rapid development of modern agriculture. We must continue to develop agricultural professional degree Graduate Education. First, we must step up publicity efforts, socially oriented agricultural sector, grassroots-oriented; clarify it with master's degree in agronomy respective disciplines at the same level, to dispel the concerns of students and employers, to attract more talented people to the ranks. Secondly, it must open up opportunities students. As appropriate to relax the restrictions on the past, students have taught professional, implementation of sub-charge training fees and other ways; again, the relevant departments and expand the professional degree in agriculture recruit and train size should develop recruitment plans. 


\subsection{To strengthen the comprehensive reform of the Agricultural Science graduate training mode, management system, teacher team building and other aspects.}

Establish and Graduate Education in Agricultural types and sizes to adapt to training mode. Curriculum system Settings must be consistent with the applied talents training goal. On the teaching methods to be abandon force-feeding, teaching methods instill more heuristic, discussion and participatory teaching methods, emphasis on mobilizing students enthusiasm and initiative to train graduate students as both profound professional basis have extensive knowledge face and human qualities of the compound talents [4]. Meanwhile, to strengthen the practice session, education and so closely integrated with production, focus on training students to master knowledge base of technical expertise itself special needs, to better suit the actual needs of the current agricultural production, faster and better for the current agriculture and rural development service.

Establish a flexible education management system. Due to graduate in Agricultural and often engaged in scientific research related to plants and animals, which would require agricultural postgraduate education and management should be more flexible. Thus, appropriate implementation of "flexible educational system." In addition, diversification of cultivation specifications and patterns are necessary for teaching arrangement more flexible [5]. To increase the flexibility of the education management reform to adapt to the characteristics of agricultural graduate education, fully mobilize and exert students' potential and creativity.

Strengthen the construction of the tutor team. We must take a variety of ways to improve the overall quality of academic ability and mentor. Such as introducing competition mechanism, to implement dynamic management of the contingent of tutors, the term evaluation, break the teacher life tenure; realize the direction of the multidisciplinary cross as a mentor; take further study to participate in academic exchanges and cooperation at home and abroad, visits abroad study, undertaken major research projects and other forms, establish a good ideological quality, high academic standards, strong activity, education, age structure reasonable tutor team.

Establish and improve agricultural graduate education quality guarantee system and quality supervision and evaluation mechanisms. Postgraduate training in macro planning unit at the same time, we must cultivate all aspects of the process, must be to micro quality control, some of the key factors in the process of continuous management, in the process of self management to achieve self-improvement and self-improvement.

In establish and improve the agricultural quality guarantee system of graduate education, at the same time, we should consider the establishment of agricultural postgraduate education quality evaluation mechanisms. Can be considered from two aspects, one is from agricultural postgraduate education within the system. Sources of such visits, the team supervisor, training the process, the quality of courses, dissertations and ideological and political work, etc., are given evaluation findings. Second, establish a social evaluation system for graduate education effectiveness and results were evaluated. That is, from society, employing units of our graduates use feedback to give a comment. In short, we want to combine our country, to establish a scientific, standardized, practical and effective quality of graduate education social evaluation system.

\section{Conclusion}

With the implementation of science and technology and "education", "developing agriculture through science and education" strategy, education reform continued to deepen, should increasingly fierce competition in the agricultural industry, agricultural research institutions, production units (including the administrative departments of agriculture and agribusiness) in all aspects of agricultural colleges and universities and the like are to cultivate high quality agricultural postgraduates given high priority. Although, our country agricultural colleges postgraduate education training there are varying degrees of problems, But as long as seize opportunities, take effective reform measures, we will accelerate the process of agricultural cultivation class high-end talent for 
China's agriculture and rural development, and the whole of society to contribute to economic development.

\section{References}

[1] Qinping Zhao. Actively explore, courage to innovate, vigorously promote the reform of graduate student training work [J]. Degrees and Graduate Education. 2010 (2).

[2] Xindian Li, etc. Try to talk about higher agricultural colleges and universities graduate student innovation ability [J]. Heilongjiang Chronicles. 2014 (1).

[3] Ruijun Xu. Modern agriculture and agricultural postgraduate education [J]. Zhejiang New Century Agricultural Research .2014 (10).

[4] Baojia Gao. Construction of agricultural postgraduate courses Training Mode Reform [J]. Higher agricultural education .2015 (6).

[5] Qingmin Zhao. Present Situation of Postgraduate Education Quality analysis and countermeasures [J]. Degrees and Graduate Education .2012 (5). 